\title{
Prediction of Permeation and Cellular Transport of Silybum marianum Extract Formulated in a Nanoemulsion by Using PAMPA and Caco-2 Cell Models*
}

\author{
Authors \\ Vieri Piazzini ${ }^{1}$, Chiara Rosseti ${ }^{1}$, Elisabetta Bigagli ${ }^{2}$, \\ Cristina Luceri $^{2}$, Anna Rita Bilia ${ }^{1}$, Maria Camilla Bergonzi ${ }^{1}$ \\ Affiliations \\ 1 Department of Chemistry, University of Florence, Sesto \\ Fiorentino, Florence, Italy \\ 2 NEUROFARBA, Department of Neurosciences, Psychology, \\ Drug Research and Child Health, Section of Pharmacology \\ and Toxicology, University of Florence, Florence, Italy
}

Key words

Silybum marianum L. Gaertn., Asteracee, nanoemulsion, solubility, PAMPA, Caco-2

received January 26, 2017

revised April 12, 2017

accepted April 22, 2017

Bibliography

DOI https://doi.org/10.1055/s-0043-110052

Published online May 4, 2017 | Planta Med 2017; 83: 1184-

1193 @ Georg Thieme Verlag KG Stuttgart · New York ।

ISSN 0032-0943

Correspondence

Maria Camilla Bergonzi

Department of Chemistry, Building ex Pharmaceutical

Sciences, University of Florence

via U. Schiff 6, 50019 Sesto Fiorentino (FI), Italy

Phone: + 390554573678

mc.bergonzi@unifi.it
Supporting information available online at
http://www.thieme-connect.de/products

\section{ABSTRACT}

The present study explores the potential of nanoemulsion, a lipid drug delivery system, to improve solubility and oral absorption of Silybum marianum extract. The optimized formulation contained $40 \mathrm{mg} / \mathrm{mL}$ of commercial extract ( $4 \% \mathrm{w} / \mathrm{w}$ ) and it was composed of $2.5 \mathrm{~g}$ labrasol (20\%) as the oil phase, $1.5 \mathrm{~g}$ cremophor EL as the surfactant, and $1 \mathrm{~g}$ labrafil as the cosurfactant (mixture surfactant/cosurfactant, $20 \%$ ).

The system was characterized by dynamic light scattering, transmission electron microscopy, and HPLC-DAD analyses in order to evaluate size, homogeneity, morphology, and encapsulation efficiency. Physical and chemical stabilities were assessed during 40 days at $4{ }^{\circ} \mathrm{C}$ and 3 months at $25^{\circ} \mathrm{C}$. Stability in simulated gastric fluid followed by simulated intestinal conditions was also considered.

In vitro permeation studies were performed to determine the suitability of the prepared nanoemulsion for oral delivery. Different models such as the parallel artificial membrane permeability assay and Caco- 2 cell lines were applied.

The nanoemulsion showed a good solubilizing effect of the extract, with a pronounced action also on its permeability, in respect to a saturated aqueous solution. The Caco-2 test confirmed the parallel artificial membrane permeability assay results and they revealed the suitability of the prepared nanoemulsion for oral delivery.

\section{Introduction}

SM (milk thistle) is annual or biennial plant of the Asteracee family. Historically, it was used to treat disorders of the liver, spleen, and gallbladder. The main group of active constituents of SM seeds, known as silymarin, consists of flavonolignans (silybin, isosylbin, silycristin, and silydianin) ( $\bullet$ Fig. 1) [1]. They have a broad spectrum of bioactivities and pharmacological activities. Well known as a hepatoprotector, silymarin is effective clinically to treat a variety of liver disorders [2-4] and certain cancers, such as breast, prostate, and skin cancers $[5,6]$.

Silymarin has been found to be beneficial in type 2 diabetes patients and a number of articles demonstrated decreases in both fasting and mean daily glucose, triglyceride, and total cholesterol levels [7-9]. However, the effectiveness of silymarin was discounted by its poor water solubility and low bioavailability after oral administration [2]. Orally administered silymarin is absorbed rapidly with a $t_{\max }$ of about $2-4 h$ and $a t_{1 / 2}$ of $6 h$ [2]. Only 20$50 \%$ of the extract is absorbed after oral administration and undergoes extensive enterohepatic circulation $[10,11]$.

Our main purpose is to search for technological strategies to overcome all the disadvantages associated with conventional for-

* Dedicated to Professor Dr. Max Wichtl in recognition of his outstanding contribution to pharmacognosy research. 


$\begin{array}{ll}\text { ABBREVIATIONS } \\ \text { AP } & \text { apical } \\ \text { BL } & \text { basolateral } \\ \text { DLS } & \text { dynamic light scattering } \\ \text { HBSS } & \text { Hank's balanced salt solution } \\ \text { HEPES } & \text { 4-(2-hydroxyethyl)-1-piperazine ethanesulfonic } \\ & \text { acid } \\ \text { LOD } & \text { detection limit } \\ \text { LOQ } & \text { quantitation limit } \\ \text { LY } & \text { lucifer yellow } \\ \text { MTS } & \text { 3-(4,5-dimethylthiazol-2-yl)-5-(3-carboxy- } \\ & \text { methoxyphenyl)-2-(4sulfophenyl)-2H-tetra- } \\ & \text { zolium } \\ \text { NE } & \text { nanoemulsion } \\ \text { PAMPA } & \text { parallel artificial membrane permeation assay } \\ \text { PDI } & \text { polydispersity index } \\ \text { PVDF } & \text { polyvinylidene fluoride } \\ \text { RT } & \text { room temperature } \\ \text { SGF } & \text { simulated gastric fluid } \\ \text { SIF } & \text { simulated intestinal fluid } \\ \text { SM } & \text { Silybum marianum L. Gaertn. } \\ \text { S } \text { mix } & \text { mixture surfactant/cosurfactant } \\ \text { TEM } & \text { transmission electron microscopy } \\ & \\ & \end{array}$

mulations, in particular to improve bioavailability after oral administration and consequently the therapeutic efficacy.

Many approaches were employed, such as $\beta$-cyclodextrin inclusion complexes [12], solid dispersion pellets [13], proliposomes [14], self-microemulsifying drug delivery systems $[15,16]$, nanoemulsions [17], and phospholipid complexes [18], in order to improve the efficacy and bioavailability of silymarin or silybin.

This study is aimed at developing a new oral formulation that can overcome the limited oral bioavailability, increasing the therapeutic efficacy of a commercial extract. The oil-in-water NE was formulated with food-acceptable components to increase solubility, stability, and ameliorate intestinal permeability of the extract's constituents.

In recent years, lipid-based formulations have been used to improve the oral bioavailability of poorly water-soluble compounds. Lipid carriers promote absorption by presenting the drug to the gastrointestinal tract in a solubilized form, increasing the solubilization capacity of the gastrointestinal fluids and in many cases, generating transiently supersaturated drug concentrations [19, 20]. NEs have attracted much interest since they are highly dispersed, stable, and transparent systems and easy to prepare. Furthermore, their nanoscopic dimensions allow for better absorption by the cell membranes. Finally, NEs show the ability to solve the problems of solubility and stability of many phytotherapeutics, nutraceuticals, and food additives $[21,22]$ because they avoid the dissolution step.

After qualitative and quantitative HPLC-DAD characterization of a commercial SM extract, it was incorporated into a selected oil-in-water NE, and its physical/chemical stabilities and release properties were investigated. NE was physically and chemically characterized with DLS, TEM, and HPLC-DAD analyses in order to evaluate size, homogeneity, morphology, and encapsulation efficiency. Stability in SGF, followed by simulated intestinal conditions, was also considered.

In vitro permeation or transport studies using different models such as the PAMPA [23] and Caco-2 cell line were also evaluated to determine the suitability of the prepared NE for oral delivery. Based on the characteristics of these two methods, these assays can be synergistically applied to an efficient and rapid investigation of permeation mechanisms in preformulation studies, not only in the case of single molecules, but also for complex matrices, such as extracts and their formulations, as reported in this study.

\section{Results and Discussion}

An HPLC-DAD method was developed to quali-quantitative characterization of the SM commercial extract. The wavelengths of 210,280 , and $350 \mathrm{~nm}$ were selected for acquiring the main constituents of the extract. In order to achieve better chromatographic separation, various linear gradients of a binary or ternary mixture of acetonitrile, water, and methanol were investigated at different flow rates by using various RP-18 columns. Finally, the gradient program described in the experimental part was selected for its separative efficiency. The chromatographic profile of the methanolic extract at $280 \mathrm{~nm}$ is reported in Fig. S1, Supporting Information. The identification of compounds was carried out by UV absorption spectra and by comparison with standard compounds and literature data [24-26]. The chromatographic conditions allowed for a good separation of two diastereoismers of silybin and sylichristin and the peaks related to taxifolin and isosilybin (Fig. S1, Supporting Information). The dried commercial extract contained $55.24 \% \mathrm{w} / \mathrm{w}$ of silymarin and $1.88 \% \mathrm{w} / \mathrm{w}$ of taxifolin, according to the literature [1].

Nest, the solubility of the extract was determined in various oils, surfactants, and cosurfactants to ascertain the appropriate components of the NE ( $\triangleright$ Table 1 ). Selected vehicles show a different influence on the solubility of the constituents compared to water. All vehicles increased the solubility of both silymarin and taxifolin. Based on the solubility results, good lipophilic phases resulted for transcutol HP and labrasol. These were mixed in different ratios with pairs of surfactant/cosurfactants $\left(S_{\text {mix }}\right)$. The solubilizing effect of transcutol is well known. It was used in several dosage forms because of its ability to solubilize many drugs including silybin [27]. Therefore, labrasol was preferred in the preparation of our NE to evaluate a new formulation.

The optimized NE was assessed for clarity and transparency by visual inspection. The best system was obtained by using labrasol as the oil and cremophor EL/labrafil as the surfactant/cosurfactant system $\left(S_{\text {mix }}\right)$ in a 1.5:1 ratio. The selection of the ingredients was driven by consideration of their toxicity and by knowledge of their mechanism of action on permeability through the gastrointestinal tract. Labrasol and, to a lesser extent, cremophor were shown to open tight junctions [28].

The existing region of each NE was obtained by phase diagram. The pseudo-ternary phase diagram was built using a water titra- 

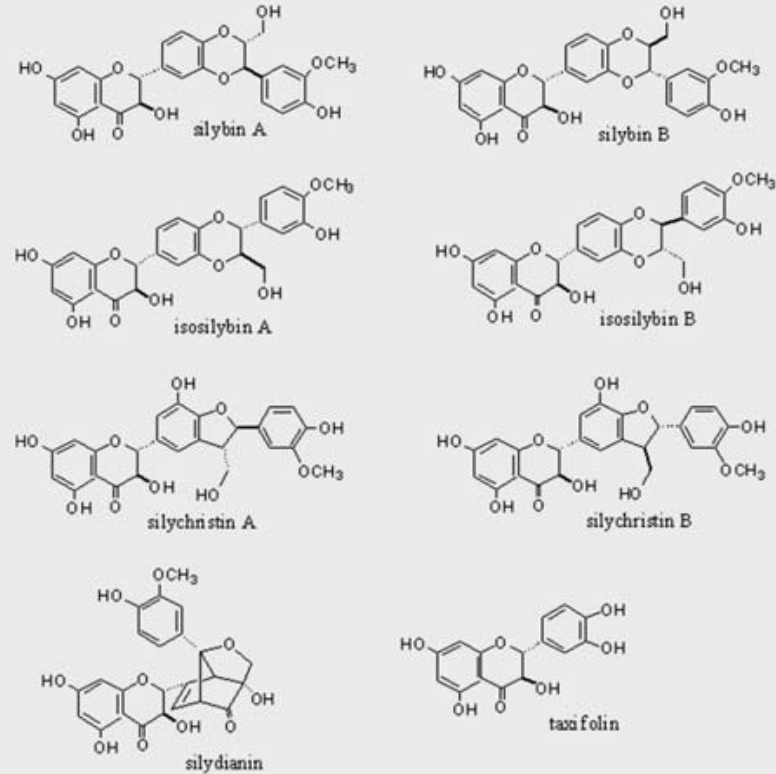

Fig. 1 Structure of main constituents of SM extract.

tion method. Each sample was visually checked after equilibrium, and determined as being a clear nanoemulsion, emulsion, or gel. - Fig. 2 (dark grey area) shows the pseudo-ternary diagram with a field of existence of a selected NE (1:1 O/S $S_{\text {mix }}$ and $\left.S_{\text {mix }} 1.5: 1\right)$. Finally, the composition resulted as $2.5 \mathrm{~g}$ of labrasol (20\%) as the oil phase, $1.5 \mathrm{~g}$ of cremophor EL as the surfactant, $1 \mathrm{~g}$ of labrafil as the cosurfactant $\left(S_{\mathrm{mix}}, 20 \%\right)$, respectively. Deionized water was added drop by drop, under gentle agitation, to each oily mixture. Its final volume was $7.0 \mathrm{~mL}(60 \%)$.

The solubility of the extract into the NE was also determined by adding increasing amounts of SM into the NE. The samples were analyzed by HPLC after $48 \mathrm{~h}$ under magnetic stirring at RT. The results were compared with data obtained with the saturated aqueous solution. The NE considerably improved the solubility of the SM extract compared to water. The extract was completely solubilized at the dosage of $40 \mathrm{mg} / \mathrm{mL}$ in respect to its aqueous solubility, which results in less than $0.3 \mathrm{mg} / \mathrm{mL}$. The amounts of constituents solubilized into the NE are reported in $>$ Table 2. A high increase of solubility was obtained for all constituents and the solubility of silymarin was ameliorated about 60 times.

Physical characterization of an empty and extract-loaded NE $(4 \% \mathrm{w} / \mathrm{w})$ confirmed the presence of a homogeneous system, with a narrow size distribution and low values of the PDI and mean diameter ( $\triangleright$ Table 3 ). These data were compared with those obtained by TEM analysis, which confirmed the presence of droplets with a size less than $40 \mathrm{~nm}$ (Fig. S2, Supporting Information).

The developed NE represents a successful tool to incorporate SM commercial extract and to significantly ameliorate its solubility. It was suitable for oral administration in terms of physical characteristics and safety of constituents.

Empty and extract-loaded formulations were stored away from light at $4{ }^{\circ} \mathrm{C}$ for 40 days in order to define their stability. Physical stability was assessed by monitoring the size of the dispersed phase by DLS. The extract-loaded NE result was stable: no phase separation occurred, the size of the droplets remained constant, the zeta potential ranged from -5.1 to $-6.6 \mathrm{mV}$, and the PDI from 0.114 to 0.179 . TEM results confirmed the data obtained by DLS analyses: sizes ranged between 30 and $40 \mathrm{~nm}$.

Chemical stability was obtained by quantifying the residual amount of the main constituents (silybin, isosilybin, silychristin, and taxifolin) of the extract by using the HPLC-DAD method reported in the experimental part.

As evidenced in $>$ Fig. $\mathbf{3}$, the concentration of silybin, isosilybin, silychristin, and taxifolin remained constant during the whole period of the test. The developed formulation showed excellent physical and chemical stability, as the size and polydispersity were unaffected and no degradation of active constituents was observed during 40 days.

The NE stability was also considered at RT $\left(25^{\circ} \mathrm{C}\right)$ during 3 months. No phase separation, creaming, or cracking occurred, and the technological characteristic of the disperse phase was unmodified (size $20.09 \pm 0.04 \mathrm{~nm}$, PDI $0.059 \pm 0.014$, zeta potential $-6.63 \pm 1.73 \mathrm{mV}$ ). The residual percentages of the constituents remained unchanged (taxifolin: $0.31 \pm 0.01 \mathrm{mg} / \mathrm{mL}$; silybin: $5.73 \pm 0.07 \mathrm{mg} / \mathrm{mL}$; isosilybin: $1.23 \pm 0.01 \mathrm{mg} / \mathrm{mL}$; silychristin: $0.80 \pm 0.05 \mathrm{mg} / \mathrm{mL})$.

An in vitro lipid digestion assay in simulated gastrointestinal medium was also performed to evidence if the NE could protect active constituents of the extract from degradation during transit through an unfavorable environment in the gastrointestinal tract until the intestine. To evaluate the suitability of the NE for this purpose, intragastric stability was tested in SGF $(\mathrm{pH} 2)$ in the presence of pepsin for $2 \mathrm{~h}$, followed by treatment with SIF $(\mathrm{pH} 7)$ in the presence of the pancreatin-lipase-bile extract mixture for $2 \mathrm{~h}$. Samples were collected and analyzed by DLS analysis to check their physical stability. The analyses confirmed the physical stability of the systems in terms of size and homogeneity. NE was stable and no aggregation or degradation phenomena occurred. Sizes of the dispersed phase of NE in SGF $(23.3 \pm 3.5 \mathrm{~nm})$ and SIF $(23.0 \pm 1.5 \mathrm{~nm})$ media remained around $20 \mathrm{~nm}$.

An in vitro release study allowed us to understand the kinetics of the release of the extract loaded in NE during $24 \mathrm{~h}$. The dissolution medium was a mixture of $\mathrm{CaCl}_{2} 750 \mathrm{mM}$ : EtOH 60:40. - Fig. 4 shows the release profile. A gradual release was found and the maximum percentage of silymarin obtained resulted in $58.5 \pm 2.69 \%$ after $24 \mathrm{~h}$. In this case, any released constituent is greatly diluted once it leaves the bag. Perhaps due to the large volume of the dissolution medium $(200 \mathrm{~mL})$ and the poor solubility of taxifolin in water, only silymarin can be quantified. Furthermore, this kind of kinetic was studied and the correlation coefficient $\left(R^{2} 0.984\right)$ is in agreement with the kinetics of release of the Hixson model [29].

PAMPA is an in vitro method for predicting passive intestinal absorption. In the last decades, it has gathered considerable interest in pharmaceutical research as a helpful complement and alternative to the Caco-2 assay.

The experiment was carried out measuring the ability of the saturated aqueous solution of the SM extract and extract-loaded NE to diffuse from the donor to acceptor compartment, through a 
- Table 1 Solubility of the constituents of SM extract in different vehicles. Data displayed as the mean \pm SD, $n=3$.

\begin{tabular}{|l|l|c|c|}
\hline & $\begin{array}{l}\text { Taxifolin } \\
(\mathbf{m g} / \mathbf{m L})\end{array}$ & $\begin{array}{l}\text { Silychristin } \\
(\mathbf{m g} / \mathbf{m L})\end{array}$ & $\begin{array}{l}\text { Silybin } \\
(\mathbf{m g} / \mathbf{m L})\end{array}$ \\
\hline Triacetin & $0.19 \pm 0.05$ & $0.35 \pm 0.01$ & $2.61 \pm 0.08$ \\
\hline Labrafil & $0.19 \pm 0.04$ & $0.27 \pm 0.09$ & $2.33 \pm 0.51$ \\
\hline Oleic acid & $0.080 \pm 0.005$ & $0.19 \pm 0.02$ & $1.98 \pm 0.11$ \\
\hline Capryol 90 & $0.69 \pm 0.02$ & $1.66 \pm 0.04$ & $8.21 \pm 0.14$ \\
\hline Labrasol ECH & $2.86 \pm 0.17$ & $17.43 \pm 0.21$ & $37.87 \pm 1.83$ \\
\hline Transcutol HP & $5.95 \pm 0.27$ & $25.12 \pm 0.93$ & $79.29 \pm 2.74$ \\
\hline Cremophor EL & $0.92 \pm 0.25$ & $2.3 \pm 0.95$ & $12.09 \pm 2.86$ \\
\hline Water & $0.047 \pm 0.01$ & $0.095 \pm 0.037$ & 0.03 \\
\hline
\end{tabular}

membrane, to evaluate the influence of the formulation on the permeability of the extract. By comparison of quantities permeated at different incubation times, we observed an increase of the amount of extract constituents permeated in comparison with a saturated aqueous solution of the extract used as a control $(\vee$ Table 4). After 30 min, the quantity of components permeated was negligible for both samples. After $6 \mathrm{~h}$, the permeation increased for the extract formulated into NE. This agrees with the fact that the NE ameliorates the solubility of flavolignans much less than that of taxifolin, probably due to different polarities and oil solubility of the constituents. In this case, the volume of the acceptor compartment was 250 mcceptotaxifolin was more easily quantifiable in this low volume in respect to the dissolution test, and the effective permeability $\left(\mathrm{P}_{\mathrm{e}}\right)$ values confirmed the increase of permeation of the extract in respect to the extract alone in water.

The $P_{e}$ of silymarin and taxifolin were calculated as reported in the literature $[30,31] . P_{e}$ was $93.5 \pm \times 10^{-6} \mathrm{~cm} / \mathrm{sec}$ for silymarin and $6.16 \pm \times 4.810^{-6} \mathrm{~cm} / \mathrm{sec}$ for taxifolin. In the case of the aqueous solution, $P_{e}$ was $44.74 \pm \times 10^{-6} \mathrm{~cm} / \mathrm{sec}$ for silymarin and $21.0 \pm 3.7 \times 10^{-6} \mathrm{~cm} / \mathrm{sec}$ for taxifolin. A required recovery $>80 \%$ for an acceptable in vitro prediction was obtained. The values (data displayed as the mean $\pm S D ; n=3$ ) confirmed that the NE also increased the permeability of the extract compared to the aqueous solution.

Caco-2, a human intestinal epithelial cell line, was used as a model to study drug absorption across the intestinal epithelium. Caco- 2 cells are the most widely and successfully used permeation models, which are employed to study passive diffusion, active transport, paracellular permeability, and active efflux [32].

The potential cytotoxicity of SM-loaded NE for Caco-2 cells was tested to find the highest non/low toxic concentrations to be used in transport experiments. After exposure for $4 \mathrm{~h}$ to a solution of NE diluted 40 times, the percentage of cell death was negligible compared to the control (untreated cells), therefore this dilution was considered acceptable for transport experiments.

In the case of the aqueous solution, silymarin and taxifolin were not detected in the BL chamber ( $\triangleright$ Table 5). On the contrary, in the case of the NE, these molecules penetrated the BL chamber $(A \rightarrow B), 61.2 \%(4.63 \mathrm{mg})$ for silymarin and $79.5 \%(0.27 \mathrm{mg})$ for taxifolin, after $4 \mathrm{~h}$ of incubation. $\mathrm{P}_{\mathrm{app}}$ values are reported in

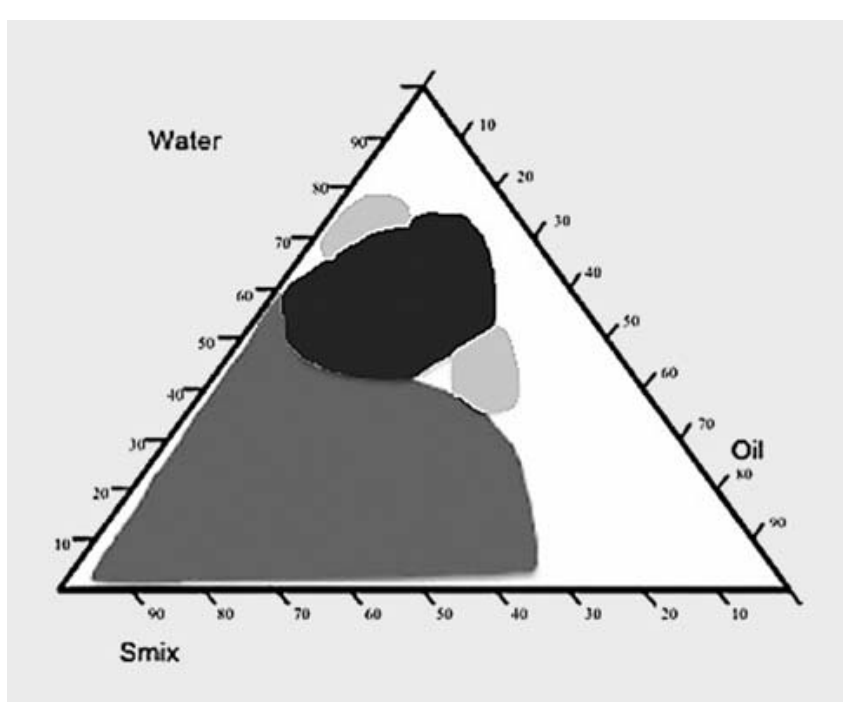

- Fig. 2 Pseudo-ternary phase diagram of microemulsion ( $\mathrm{S}_{\text {mix }}$ : $1: 1$, labrasol and cremophor EL). Light gray: gel; dark gray: nanoemulsion; white: turbidity.

- Table 5. A recovery $>80 \%$ was obtained. Therefore, the formulations provided enhanced intestinal permeability of the SM extract. This fact is certainly due to the presence of surfactant used as a stabilizer of the internal phase. As previously reported, the surfactants enhance drug permeability in many ways, such as by increasing transcellular permeability and by inhibiting the efflux transport systems [33,34]. Labrasol and labrafil are nonaqueous excipients used as solvents or cosolvents for absorption enhancing of oral and/or topical drug formulations $[35,36]$. They contain mono-, di- and triglycerides with mono- and diesters of polyethylene glycol and fatty acids, and they are applied as solubilizers, surfactants, and absorption promoters [37]. Labrasol showed a high tolerance and low toxicity in rats [38]. According to the results of Delongeas et al., $5 \mathrm{~mL} / \mathrm{kg} /$ day was an acceptable and nontoxic volume for use of a labrasol/labrafil/transcutol mixture as a vehicle for poorly water-soluble drugs [39]. Furthermore, labrasol and, to a lesser extent, cremophor were shown to open tight junctions 
- Table 2 Solubility of the SM extract into NE vs. water. Data are displayed as the mean $\pm S D, n=3$.

\begin{tabular}{|l|l|l|l|l|l|}
\hline & Taxifolin $(\mathbf{m g} / \mathbf{m L})$ & Silychristin $(\mathbf{m g} / \mathbf{m L})$ & Silybin $(\mathbf{m g} / \mathbf{m L})$ & Isosylibin $(\mathbf{m g} / \mathbf{m L})$ & Silymarin $(\mathbf{m g} / \mathbf{m L})$ \\
\hline Water & $0.047 \pm 0.010$ & $0.095 \pm 0.037$ & $0.025 \pm 0.010$ & $0.009 \pm 0.001$ & $0.13 \pm 0.01$ \\
\hline NE & $0.34 \pm 0.06$ & $0.77 \pm 0.03$ & $5.71 \pm 0.14$ & $1.12 \pm 0.05$ & $7.60 \pm 0.07$ \\
\hline
\end{tabular}

- Table 3 Technological characterization of empty and SM extractloaded NE. Data are the mean $\pm S D, n=3$.

\begin{tabular}{|l|l|l|l|}
\hline Sample & Size & Polydisperison & Z-D)dpotential \\
\hline Empty NE & $22.27 \pm 1.08$ & $0.106 \pm 0.06$ & $-1.1 \pm 0.31 \mathrm{mV}$ \\
\hline $\begin{array}{l}\text { NE (40 mg/ } \\
\text { mL of SM) }\end{array}$ & $21.29 \pm 0.41$ & $0.114 \pm 0.07$ & $-5.1 \pm 0.71 \mathrm{mV}$ \\
\hline
\end{tabular}

[28]. The safety of the components selected for our NE is another important aspect for oral administration.

To elucidate the possible mechanism to penetrate Caco-2 membranes, other studies were carried out by evaluating the permeability in the opposite direction $(B \rightarrow A)$ and by using verapamil as a P-gp inhibitor to obtain, on indication, the involvement of an active process [40]. The results are reported in $>$ Table 5 . The efflux ratio was 0.82 for silymarin and 1 for taxifolin. No difference in permeation was observed and the transport result was mainly passive [41]. The Caco-2 results confirmed the ability of the NE to increase the permeation of the extract, as follows from the PAMPA test.

In vitro transport studies using PAMPA and Caco-2 models provided useful information about dissolution and permeation/absorption aspects, which could be correlated further to in vivo bioavailability studies. They proved that the NE successfully enhances the permeation of the extract compared to the aqueous solution by suggesting that the developed formulation will increase the therapeutic effects of the SM extract.

\section{Materials and Methods}

\section{Materials}

The SM dry extract was supplied by Bionorica. The dry extract complies with the monograph Silybi mariani extractum siccum raffinatum et normatum (Ph. Eur. 8.0/2071) of the European Pharmacopoeia. The DER was 24-27:1 and the extraction solvent was acetone. Storage conditions: tightly closed, dry, protected from light, $15-25^{\circ} \mathrm{C}$. Voucher specimen: 1007-2014.

Taxifolin (purity $\geq 99 \%$ ) was from Extrasynthese and silycristin (purity $\geq 95 \%$ ) and silybin (purity $\geq 98 \%$ ) were from Sigma-Aldrich. Cremophor EL, triacetin, ethanol analytical reagent, HPLC grade acetonitrile and methanol, formic acid $(\geq 98 \%)$, cholesterol, lecithin, dichloromethane, DMSO, 1,7-Octadiene ( $\geq 98 \%)$, PBS bioperformance certified, lipase from porcine pancreas, pepsin from porcine gastric mucose, bile salts, and $\mathrm{HCl}$ were purchased from Sigma-Aldrich. Oleic acid was from Farmitalia, Carlo Erba SpA. Labrasol ECH, capryol 90, and transcutol HP were kindly provided by Gattefossé. Water was purified by a Milli-Qplus system from Millipore. Phosphotungstic acid (PTA) was from Electron Microscopy Sciences.

\section{Methods}

Preparation of Silybum marianum extract sample for HPLC-DAD analysis

A commercial extract (500 $\mathrm{mg}$ accurately weight) was suspended in $20 \mathrm{~mL}$ of methanol, ultrasonicated for $30 \mathrm{~min}$, and filtered. The extraction was repeated three times. The filtrate was evaporated until dryness. Then, the residue was dissolved in methanol to prepare the sample for HPLC-DAD analysis. Aqueous solubility was determined by dissolving the extract in deionized water until saturation at RT. The undissolved solid was eliminated by centrifugation and the solution was analyzed by HPLC.

\section{Preparation of standard solutions}

Standard solutions were freshly prepared by dissolution of standard compounds in methanol to obtain a final concentration of $0.5 \mathrm{mg} / \mathrm{mL}$. The linearity range of response was determined for taxifolin, silycristin, and silybin. All the calibration curves had coefficients of linear correlation $R^{2} \geq 0.999$.

LOD and LOQ were determined by calculation of the signal-tonoise ratio. LOD resulted in $5.05 \mathrm{ng}$ for taxifolin, $6.9 \mathrm{ng}$ for silycristin, and $7.5 \mathrm{ng}$ for silybin. LOQ resulted in $12.2 \mathrm{ng}$ for taxifolin, $11.7 \mathrm{ng}$ for silycristin, and $10 \mathrm{ng}$ for silybin.

\section{HPLC-DAD analysis}

The separation of SM extract constituents was carried out using an HP 1100 liquid chromatograph equipped with a DAD detector. A $150 \mathrm{~mm} \times 4.6 \mathrm{~mm}$ i.d., $5 \mathrm{~m}$ Zorbax Eclipse XDB, RP18 column was used. The mobile phases were (A) formic acid/water $\mathrm{pH} 3.2$, (B) $\mathrm{CH}_{3} \mathrm{CN}$, and (C) $\mathrm{CH}_{3} \mathrm{OH}$. The flow rate was $0.6 \mathrm{~mL} / \mathrm{min}$ and the temperature was set to $26^{\circ} \mathrm{C}$. The injection volume was $20 \mu \mathrm{L}$. The UV/vis spectra were recorded in the range of 200$700 \mathrm{~nm}$ and the chromatograms were acquired at 210,280, and $350 \mathrm{~nm}$.

The following mobile phase was applied: $0-10 \mathrm{~min}, 63-58 \% \mathrm{~A}$, $15-20 \%$ B, $22-22 \%$ C; $10-15$ min, $58-30 \%$ A, $20-30 \%$ B, $22-40 \%$ C; $15-20$ min $30-30 \%$ A, $30-30 \%$ B, $40-40 \%$ C; $20-25$ min, 30$63 \% \mathrm{~A}, 30-15 \% \mathrm{~B}, 40-22 \% \mathrm{C}$ with an equilibration time of $5 \mathrm{~min}$.

\section{Solubility studies}

The extract's solubility in different vehicles was measured to find an appropriate medium with a good solubilizing capacity of the SM extract and useful either as a lipophilic phase or (co)surfac- 


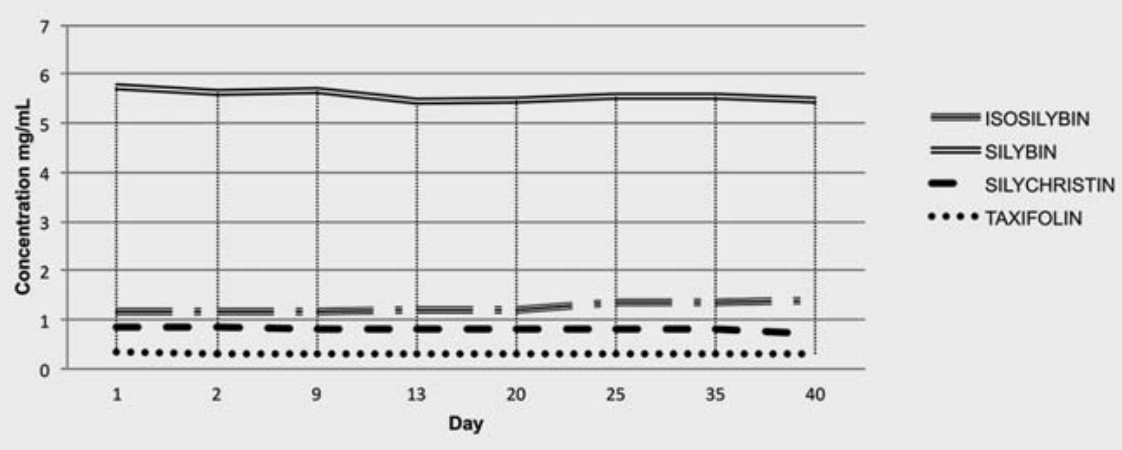

- Fig. 3 Chemical stability of the main constituents of the extract in the stability test at $4^{\circ} \mathrm{C}($ data are the mean $\pm S D, n=3$ ).

tant. An excess amount of SM extract was added to $5 \mathrm{~mL}$ of each selected solvent (triacetin, tocopherol acetate, oleic acid, labrafil, capryol 90 cremophor EL, labrasol ECH, transcutol HP, and labrafac PG ECH, water). Each mixture was shaken at $25^{\circ} \mathrm{C}$ for $24 \mathrm{~h}$, and then was centrifugated at $13148 \times \mathrm{g}$ for $10 \mathrm{~min}$. The concentration of the components of the extract was determined by HPLC after dilution with methanol/dichloromethane $(3: 2)$. The analyses were performed in triplicate.

\section{Construction of ternary phase diagram}

Pseudo-ternary phase diagrams were constructed using Chemix School version 3.60 software to obtain the concentration range of all components in which they form NE. The pseudo-ternary phase diagrams were constructed using the water titration method. Surfactant and cosurfactant were mixed at different weight ratios $\left(S_{\text {mix }}\right)$. For each $S_{\text {mix }}$ ratio, a pseudo-ternary phase diagram was elaborated by testing the weight ratio of oil/ $S_{\text {mix }}$ of $0: 100$, $5: 95,10: 90,20: 80,30: 70,40: 60,50: 50,60: 40,70: 30$, $80: 20$, and $90: 10$. Each oil-S $S_{\text {mix }}$ mixture was diluted under vigorous stirring dropwise with water. After equilibrium, each sample was visually checked and the phase boundary was determined by observing the changes in the sample appearance from turbid to transparent or from transparent to turbid, and by evaluating if $\mathrm{NE}$, emulsion, or gel was present.

\section{Solubility of Silybum marianum extract into nanoemulsion}

The ability of NE to solubilize the extract was investigated and compared with the respective aqueous, micellar solution of surfactant or oil solution. In order to determine the maximum loading capacity of the NE, an extract-loaded formulation was prepared by dissolving increasing amounts of extract into the NE. The solution was stirred for $24 \mathrm{~h}$ at $25^{\circ} \mathrm{C}$ and protected from light.

The final NE was obtained by dissolving the extract into the NE $(40 \mathrm{mg} / \mathrm{mL})$ and stirring to form a clear and transparent dispersion. The resulting formulation was tightly sealed and stored at $4^{\circ} \mathrm{C}$ temperature. The quantity of constituents solubilized was defined by HPLC-DAD analysis at $280 \mathrm{~nm}$ after dilution with methanol/dichloromethane $(3: 2)$. The analyses were performed in triplicate.

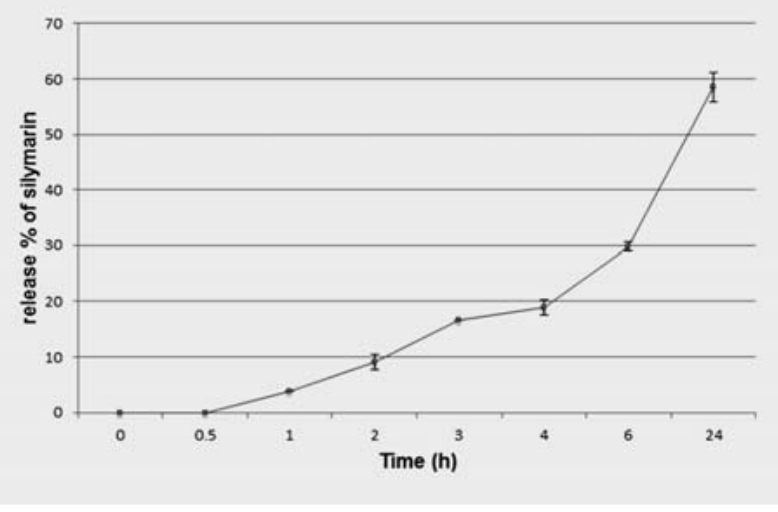

- Fig. 4 In vitro release profile of silymarin (data are the mean \pm SD, $\mathrm{n}=3)$.

- Table 4 Quantity $(\mathrm{mg})$ of silymarin and taxifolin permeated in the PAMPA test. Data are the mean $\pm S D, n=3$.

\begin{tabular}{|l|l|l|l|}
$\begin{array}{l}\text { Incubation } \\
\text { time }\end{array}$ & Constituents & NE & $\begin{array}{l}\text { Aqueous } \\
\text { solution }\end{array}$ \\
\hline $2 \mathrm{~h}$ & Silymarin & $0.220 \pm 0.006$ & $0.023 \pm 0.002$ \\
\hline & Taxifolin & $6.37 \times 10^{-3}$ & $0.4 \times 10^{-3}$ \\
\hline \multirow{2}{*}{$\mathrm{h}$} & Silymarin & $0.570 \pm 0.041$ & $0.079 \pm 0.002$ \\
\hline \multirow{2}{*}{$\mathrm{h}$} & Taxifolin & $0.028 \pm 0.005$ & $0.002 \pm 0.001$ \\
\hline & Silymarin & $0.665 \pm 0.012$ & $0.112 \pm 0.003$ \\
\hline & Taxifolin & $0.034 \pm 0.005$ & $0.004 \pm 0.001$ \\
\hline
\end{tabular}

\section{Particle size analysis and zeta potential}

Droplet sizes of the developed NE were measured by a DLS, Zsizer Nano series ZS90 (Malvern Instruments) equipped with a JDS Uniphase $22 \mathrm{~mW}$ He-Ne laser operating at $632.8 \mathrm{~mm}$, an optical fiber-based detector, a digital LV/LSE-5003 correlator, and a temperature controller (Julabo water bath) set at $25^{\circ} \mathrm{C}$. Time correlation functions were analyzed to obtain the hydrodynamic diameter of the particles (Zh) and the particle size distribution (PDI) us- 
- Table $5 P_{\text {app }}$ values $(\mathrm{cm} / \mathrm{s})$ of silymarin and taxifolin in the Caco-2 test, after $4 \mathrm{~h} ; \mathrm{A} \rightarrow \mathrm{B}$ : from $\mathrm{AP}$ to $\mathrm{BL}$ compartment; $\mathrm{B} \rightarrow \mathrm{A}$ from $\mathrm{BL}$ to $A P$ compartment. NE: nanoemulsion (data are the mean $\pm S D$, $n=3)$.

\begin{tabular}{|l|l|l|}
\hline Sample & Silymarin & Taxifolin \\
\hline Extract $(\mathbf{A} \rightarrow \mathbf{B})$ & n.d. & n.d. \\
\hline NE $(\mathbf{A} \rightarrow \mathbf{B})$ & $51.50 \times 10^{-6}$ & $66.93 \times 10^{-6}$ \\
\hline $\mathbf{N E}(\mathbf{A} \rightarrow \mathbf{B})$ with verapamile & $53.50 \times 10^{-6}$ & $65.92 \times 10^{-6}$ \\
\hline $\mathbf{N E}(\mathbf{B} \rightarrow \mathbf{A})$ & $42.19 \times 10^{-6}$ & $61.36 \times 10^{-6}$ \\
\hline
\end{tabular}

ing ALV-60X0 software V.3.X provided by Malvern. Autocorrelation functions were analyzed by the Cumulants method, fitting a single exponential to the correlation function to obtain particle size distribution. Scattering was measured in an optical quality $4 \mathrm{~mL}$ borosilicate cell at a $90^{\circ}$ angle, diluting the samples in distilled water. Zeta potentials were measured using the same instrument for all samples, and an average of three measurements at a stationary level were taken. The temperature was kept constant at $25^{\circ} \mathrm{C}$ by a Haake temperature controller. The zeta potential was calculated from the electrophoretic mobility using the Henry correction to Smoluchowski's equation.

\section{Morphological characterization}

Morphology and structure of the NE were studied using a TEM (Jeol Jem 1010). Ten $\mathrm{mL}$ of NE after appropriate dilution were applied to a carbon film-covered copper grid. Most of the dispersion was blotted from the grid with filter paper to form a thin film specimen, which was stained with a phosphotungstic acid solution ( $1 \% \mathrm{w} / \mathrm{v}$ in sterile water). The samples were dried for $3 \mathrm{~min}$ and then were examined under a JEOL 1010 electron microscope and photographed at an accelerating voltage of $64 \mathrm{kV}$.

\section{In vitro release studies}

The dialysis bag method was applied to study the extract release from the NE using a mixture of $\mathrm{CaCl}_{2} 750 \mathrm{mM}(\mathrm{pH} 7)$ : $\mathrm{EtOH} 60: 40$ as a dissolution medium. Release was monitored for $24 \mathrm{~h}$. The dialysis bags were hydrated before use. The bag containing $1 \mathrm{~mL}$ of NE was placed in a beaker containing $200 \mathrm{~mL}$ of dissolution medium maintained at $37 \pm 0.5^{\circ} \mathrm{C}$ under magnetic stirring. At different time intervals, aliquots of the dissolution medium were withdrawn and replaced with the same volume of fresh medium to maintain the sink conditions. The samples were suitably diluted and analyzed by HPLC-DAD for quantification of the constituents of the SM extract. All of the operations were carried out in triplicate.

The percentage of silymarin released in the medium at $\mathrm{pH} 7$ at each point time was calculated by applying the following formula:

$\%$ Silymarin released $_{\mathrm{t}}=\frac{\mathrm{mg} \text { silymarin }_{\mathrm{t}}}{\mathrm{mg} \text { silymarin }_{\mathrm{tot}}} \times 100$ where $\mathrm{mg}$ silymarin $_{\mathrm{t}}=\mathrm{mg}$ compound released for each time point $t$ and $\mathrm{mg}$ silymarin tot $=$ total $\mathrm{mg}$ of silymarin loaded in the NE.

\section{Stability studies}

In order to evaluate the stability of empty and extract-loaded NEs, the samples were inserted into sealed glass vials and stored at $4{ }^{\circ} \mathrm{C}$ for 40 days and at RT $\left(25^{\circ} \mathrm{C}\right)$ for three months. Chemical and physical stabilities were studied by monitoring the occurrence of phase separation, dispersed phase size, and drug content at predetermined intervals by DLS and HPLC-DAD analyses.

Furthermore, the samples were diluted 10-, 20-, and 30-fold with distilled water to mimic the physiological dilution process after oral administration. The dilutions were followed by gentle vortexing for $2 \mathrm{~min}$ at RT. The intragastric stability was tested in SGF as described earlier [42]. Briefly, $5 \mathrm{~mL}$ of NE were suspended in $5 \mathrm{~mL} \mathrm{SGF}(0.32 \% \mathrm{w} / \mathrm{v}$ pepsin, $2 \mathrm{~g}$ of sodium chloride, and $7 \mathrm{~mL}$ $\mathrm{HCl}$ dissolved in $1 \mathrm{~L}$ water and $\mathrm{pH}$ adjusted to 1.8 using $1 \mathrm{M} \mathrm{HCl}$ ) and incubated in a water bath at $37^{\circ} \mathrm{C}$ under a shaking speed of 100 strokes/min. After $2 \mathrm{~h}$, the sample was collected to analyze the size and PDI.

After digestion in simulated stomach conditions, a previous sample was subjected to digestion under simulated intestinal conditions containing an intestinal enzyme complex (lipase $0.4 \mathrm{mg} /$ $\mathrm{mL}$, bile salts $0.7 \mathrm{mg} / \mathrm{mL}$, and pancreatin $0.5 \mathrm{mg} / \mathrm{mL}$ ) and calcium chloride solution $750 \mathrm{mM}$ at $\mathrm{pH} 7.0,37^{\circ} \mathrm{C}$ under a shaking speed of 100 strokes/min. After $2 \mathrm{~h}$ digestion in SIF, the sample was collected and its physical stability was checked by DLS analysis.

\section{In vitro parallel artificial membrane permeability assay}

The assay was carried out in a 96-well, MultiScreen-IP PAMPA (Millipore corporation) filter plate. The ability of compounds to diffuse from a donor compartment, through a PVDF membrane filter pretreated with a lipid-containing organic solvent, into an acceptor compartment was evaluated. Five $\mu \mathrm{L}$ of lecithin $(10 \mathrm{~g} / \mathrm{L})$ and cholesterol $(8 \mathrm{~g} / \mathrm{L})$ in 1,7-octadiene solution were added to the filter of each well. Immediately after the application of the artificial membrane, $250 \mu \mathrm{L}$ of drug-containing donor solutions (saturated solution of the extract in water and SM-loaded NE, $40 \mathrm{mg} /$ $\mathrm{mL}$ ) were added to each well of the donor plate. Next, $250 \mu \mathrm{L}$ of buffer $(0.05 \mathrm{~mL} / \mathrm{mL}$ DMSO/PBS, $\mathrm{pH}$ 7.4) were added to each well of the acceptor plate. The donor plate was then placed into acceptor the plate, ensuring that the underside of the membrane was in contact with the buffer. The plate was covered and incubated at RT under shaking for $6 \mathrm{~h}$ and permeation was evaluated at $0.5,2,4$, and $6 \mathrm{~h}$.

After incubation for $6 \mathrm{~h}$, the contents silymarin and taxifolin into the donor and receptor compartments were analyzed by HPLC-DAD. The experiment was performed in triplicate and the mean of three samples was used in the data analysis.

Permeability of the compounds was calculated using the following formula [43]:

$P_{e}=-\ln \left[1-C_{A}(t) / C_{\text {equilibrium }}\right] / A \times\left(1 / V_{D}+1 / V_{A}\right) \times t$

where $P_{e}$ is the permeability in the unit of $\mathrm{cm} / \mathrm{s}$. $A=$ effective filter area $=f \times 0.3 \mathrm{~cm}^{2}$, where $f=$ apparent porosity of the filter, $V_{D}=$ 
donor well volume $=0.3 \mathrm{ml}, \mathrm{V}_{\mathrm{A}}=$ receptor well volume $=0.2 \mathrm{ml}$, $\mathrm{t}=$ incubation time $(\mathrm{s}), \mathrm{C}_{\mathrm{A}}(\mathrm{t})=$ compound concentration in the receptor well at time $t, C_{D}(t)=$ compound concentration in donor well at time $t$, and

$C_{\text {equilibrium }}=\left[C_{D}(t) \times V_{D}+C_{A}(t) \times V_{A}\right] /\left(V_{D}+V_{A}\right)$.

\section{Cell culture}

The human colon carcinoma cell line Caco-2 was kindly provided by Prof. Masini (University of Florence). Cells were cultured in DMEM supplemented with $20 \%$ heat-inactivated fetal calf serum, $1 \%$ L-glutamine, and $1 \%$ penicillin/streptomycin. Caco- 2 cells were incubated at $37^{\circ} \mathrm{C}$ in a humidified atmosphere containing $5 \% \mathrm{CO}_{2}$. Upon reaching $80 \%$ confluence, cells were subcultured weekly at a split ratio of $1: 3$ by trypsinization.

\section{3-(4,5-Dimethylthiazol-2-yl)-5-(3-carboxymethoxyphenyl)- 2-(4sulfophenyl)-2H-tetrazolium assay for cell viability}

Viability analysis was performed using a Cell Titer 96 Aqueous One Solution Cell Proliferation MTS Assay Kit (Promega Madison). In brief, Caco-2 cells were transferred to flat bottom 96-well tissue culture plates (Corning) at a seeding density of $5 \times 10^{3}$ cells/well and allowed to grow for $24 \mathrm{~h}$ under the conditions detailed above. For the MTS assay, the culture medium was removed and replaced with fresh medium containing SM-loaded NE $(5 \mathrm{mg} / \mathrm{mL} ; 1: 100$ $1: 300$ dilution) and the cells were incubated for a further 4 or $24 \mathrm{~h}$. The cells were then exposed to MTS solution and allowed to incubate for $2 \mathrm{~h}$ at $37^{\circ} \mathrm{C}$. The product of the reaction was measured at $490 \mathrm{~nm}$ using a spectrophotometer (Multilabel Counter 1240 Victor 3, Perkin Elmer). Cell death was expressed as a percentage of values obtained from the control (untreated cells calculated from three replicates of each NE dilution).

\section{Cell culture for transport studies}

For transport studies, cells were seeded at 50000 cells/well in cell culture inserts with PET (polyethylene terephthalate) membranes ( $0.4 \mu \mathrm{m}$ pore size, $0.33 \mathrm{~cm}^{2}$ growth surface area; BRAND). Culture medium (DMEM) was added to AP $(0.5 \mathrm{~mL})$ and $\mathrm{BL}(1.5 \mathrm{~mL})$ sides, and was replaced every other day for the first week and daily thereafter. Cells were let to differentiate for 18-21 days.

\section{Monolayer integrity}

The integrity of the layer was evaluated with the LY permeability assay according to lacomino et al. [44]. LY was diluted in transport buffer (HBSS with $\mathrm{Ca}^{2+}, \mathrm{Mg}^{2+}, 25$ mM HEPES, pH 7.4) and added to the AP compartment at a final concentration of $100 \mu \mathrm{M}$. After incubation at $37^{\circ} \mathrm{C}$ for $1 \mathrm{~h}$, the HBSS in the BL chamber was collected, and the concentration of LY was determined by using $485 \mathrm{~nm}$ excitation and $530 \mathrm{~nm}$ emission on a fluorescence plate reader (Multilabel Counter 1240 Victor 3, Perkin Elmer). The percentage of AP to BL permeability was calculated according to the following equation:

$\%$ Permeability $=\frac{\text { fluorescence in the BL }- \text { blank }}{\text { fluorescence LY }- \text { blank }} \times 100$
The critical maximum flux of LY to identify leaky monolayers was estimated to be less than $3 \%$ of the starting concentration.

\section{Transport experiments}

Transport study was performed according to Hubatsch et al. [41]. Before the transport study, the culture medium (DMEM) was replaced with preheated $\left(37^{\circ} \mathrm{C}\right)$ transport HBSS medium supplemented with $25 \mathrm{mM}$ HEPES ( $\mathrm{pH} 7.4)$. After the cell monolayer was equilibrated for $30 \mathrm{~min}$ at $37^{\circ} \mathrm{C}$, Caco-2 cells were treated for $4 \mathrm{~h}$ with different dilutions of SM-loaded NE in HBSS in the AP chamber, while the BL chamber contained only HBSS.

For the test, $0.5 \mathrm{~mL}$ of aqueous saturated solution of te extract or NE diluted 40-fold with culture medium was added to the AP side, while the BL side was filled with culture medium. At predetermined intervals (30 min, 1, 2, $4 \mathrm{~h}$ ), $0.3 \mathrm{~mL}$ of medium in the $\mathrm{BL}$ side was taken for HPLC analyses and replaced with the same volume of fresh HBSS. At the end of the experiments, the integrity of the layer was reevaluated with the LY permeability assay as described above.

Apparent permeability coefficients $\left(\mathrm{P}_{\mathrm{app}}\right)$ were calculated according to the following formula:

$\mathrm{P}_{\mathrm{app}}=\frac{\Delta \mathrm{Q} / \Delta \mathrm{t}}{\mathrm{C}_{0} \times \mathrm{A}}$

where $\Delta \mathrm{Q} / \Delta \mathrm{t}$ indicates the linear appearance rate of mass in the basolateral side, $C_{0}=$ initial concentration in the $A p$ side, and $A=$ surface area (i.e., $0.33 \mathrm{~cm}^{2}$ ).

Recovery in the parallel artificial membrane permeation assay and Caco-2 tests

The recovery (mass balance) is defined as the sum of the drug recovered from the acceptor chamber and the drug remaining in the donor chamber at the end of the experiment, divided by the initial donor amount. Recovery for silymarin and taxifolin was calculated according to the following equation:

Recovery $(\%)=\frac{C_{D f} V_{D}+C_{R f} V_{R}}{C_{D 0} V_{D}} \times 100$

where $C_{D f}$ and $C_{R f}$ are the final concentrations of the compound in the donor and receiver compartments, respectively, $C_{D 0}$ is the initial concentration in the donor compartment, and $V_{D}$ and $V_{R}$ are the volumes in the donor and receiver compartments, respectively. All results are expressed as mean \pm SD.

\section{Statistical analysis}

Experiments were repeated three times and the results are expressed as the mean \pm standard deviation. Statistical significance was calculated by Student's t-test with a statistical significance level set at $\mathrm{p}<0.05$.

\section{Supporting information}

An HPLC profile of SM extract and TEM images of empty and extract loaded NE are available as Supporting Information. 


\section{Acknowledgements}

Financial support was granted by Global Research Initiative 2013 of Bionorica SE. Dott.ssa M. Cristina Salvatici Centro di Microscopie Elettroniche "Laura Bonzi”, ICCOM, and Consiglio Nazionale delle Ricerche (CNR) is gratefully acknowledged.

Conflict of Interest

The authors declare no conflict of interest.

\section{References}

[1] Scientific Foundation for Herbal Medicinal Products. ESCOP Monographs, Second Edition: Supplement 2009. New York, USA: Thieme; 2009: 222-248

[2] Pepping J. Milk thistle: Silybum marianum. Am J Health System Pharmacy 1999; 56: 1195-1197

[3] Luper S. A review of plants used in the treatment of liver disease: part 1. Altern Med Rev 1998; 3: 410-421

[4] O'Hara MA, Kiefer D, Farrell K, Kemper K. A review of 12 commonly used medicinal herbs. Arch Fam Med 1998; 7: 523-536

[5] Xiaolin Z, Feyes DK, Agarwal R. Anticarcinogenic effect of a flavonoid antioxidant, silymarin, in human breast cancer cells MDA-MB 468: induction of G1 arrest through an increase in Cip1/p21 concomitant with a decrease in kinase activity of cyclin-dependent kinases and associated cyclins. Clin Cancer Res 1998; 4: 1055-1064

[6] Xiaolin Z, Grasso AW, Kung H], Agarwal R. A flavonoid antioxidant, silymarin, inhibits activation of erbB1 signaling and induces cyclin-dependent kinase inhibitors, G1 arrest, and anticarcinogenic effects in human prostate carcinoma DU145 cells. Cancer Res 1998; 58: 1920-1929

[7] Velussi M, Cernigoi AM, De Monte A, Dapas F, Caffau C. Long-term (12 months) treatment with an anti-oxidant drug (silymarin) is effective on hyperinsulinemia, exogenous insulin need and malondialdehyde levels in cirrhotic diabetic patients. J Hepatol 1997; 26: 871-879

[8] Lirussi F, Beccarello A, Zanette G, De Monte A, Donadon V. Silybin-betacyclodextrin in the treatment of patients with diabetes mellitus and alcoholic liver disease. Efficacy study of a new preparation of an anti-oxidant agent. Diabetes Nutr Metab 2002; 15: 222-231

[9] Huseini HF, Larijani B, Heshmat R, Fakhrzadeh H, Radjabipour B. The efficacy of Silybum marianum (L.) Gaertn. (Silymarin) in the treatment of type II diabetes: a randomized, double-blind, placebo-controlled, clinical trial. Phytother Res 2006; 20: 1036-1039

[10] Morazzoni P, Montalbetti A, Malandrino S, Pifferi G. Comparative pharmacokinetics of silipide and silymarin in rats. Eur J Drug Metab Ph 1993; 18: $289-297$

[11] Lorenz D, Lücker PW, Mennicke WH, Wetzelsberger N. Pharmacokinetic studies with silymarin in human serum and bile. Method Find Exp Clin 1984; 6: 655-661

[12] Arcari M, Brambilla A, Brandt A, Caponi R, Corsi G, Di Rella M, Solinas F, Wachter WP. A new inclusion complex of silibinin and beta-cyclodextrins: in vitro dissolution kinetics and in vivo absorption in comparison with traditional formulations. Boll Chim Farm 1992; 131: 205-209

[13] Sun NY, Wei XL, Wu B], Chen J, Lu Y, Wu W. Enhanced dissolution of silymarin/polyvinylpyrrolidone solid dispersion pellets prepared by a onestep fluid-bed coating technique. Powder Technol 2008; 182: 72-80

[14] Xiao YY, Song YM, Chen ZP, Ping QN. Preparation of silymarin proliposome: a new way to increase oral bioavailability of silymarin in beagle dogs. Int J Pharm 2006; 319: 162-168
[15] Wu W, Wang Y, Que L. Enhanced bioavailability of silymarin by selfmicroemulsifying drug delivery system. Eur J Pharm Biopharm 2006; 63: 288-294

[16] Woo JS, Kim TS, Park JH, Chi SC. Formulation and biopharmaceutical evaluation of silymarin using SMEDDS. Arch Pharm Res 2007; 30: 82-89

[17] Parveen R, Baboota S, Ali J, Ahuja A, Vasudev SS, Ahmad S. Oil based nanocarrier for improved oral delivery of silymarin: in vitro and in vivo studies. Int J Pharm 2011; 413: 245-253

[18] Xiao YY, Song YM, Chen ZP, Ping QN. Preparation of silybin-phospholipid complex and its bioavailability in rats. Acta Pharmacol Sin 2005; 40: 611-617

[19] Porter CJH, Trevaskis NL, Charman WN. Lipids and lipid-based formulations: optimizing the oral delivery of lipophilic drugs. Nature Rev Drug Discov 2007; 6: 231-248

[20] Porter CJH, Pouton CW, Cuine JF, Charman WN. Enhancing intestinal drug solubilisation using lipid-based delivery systems. Adv Drug Deliv Rev 2008; 60: 673-691

[21] Bergonzi MC, Hamdouch R, Mazzacuva F, Isacchi B, Bilia AR. Optimization, characterization and in vitro evaluation of curcumin microemulsions. LWT-Food Sci Techn 2014; 59: 148-155

[22] Piazzini V, Monteforte E, Luceri C, Bigagli E, Bilia AR, Bergonzi MC. Nanoemulsion for improving solubility and permeability of Vitex agnus-castus extract: formulation and in vitro evaluation using PAMPA and Caco-2 approaches. Drug Deliv 2017; 24: 380-390

[23] Kansy M, Senner F, Gubernator K. Physicochemical high throughput screening: parallel artificial membrane permeation assay in the description of passive absorption processes. J Med Chem 1998; 41: 1007-1010

[24] Shibano M, Lin AS, Itokawa H, Lee KH. Separation and characterization of active flavonolignans of Silybum marianum by liquid chromatography connected with hybrid ion-trap and time-of-flight mass spectrometry (LC-MS/IT-TOF). J Nat Prod 2007; 70: 1424-1428

[25] Quaglia MG, Bossù E, Donati E, Mazzanti G, Brandt A. Determination of silymarine in the extract from the dried Silybum marianum fruits by high performance liquid chromatography and capillary electrophoresis. J Pharm Biomed Anal 1999; 19: 435-442

[26] Wang K, Zhang H, Shen L, Du Q, Li J. Rapid separation and characterization of active flavonolignans of Silybum marianum by ultra-performance liquid chromatography coupled with electrospray tandem mass spectrometry. J Pharm Biomed Anal 2010; 53: 1053-1057

[27] Woo JS, Kim TS, Park JH, Chi SC. Formulation and biopharmaceutical evaluation of silymarin using SMEDDS. Arch Pharm Res 2007; 30: 82-89

[28] Sha X, Yan G, Wu Y, Li J, Fang X. Effect of self-microemulsifying drug delivery systems containing labrasol on tight junctions in Caco-2 cells. Eur J Pharm Sci 2005; 24: 447-486

[29] Dash S, Murthy PN, Nath L, Chowdhury P. Kinetic modeling on drug release from controlled drug delivery systems. Acta Pol Pharm 2010; 67: 217-223

[30] Chen X, Murawski A, Patel K, Crespi CL, Balimane PV. A novel design of artificial membrane for improving the PAMPA model. Pharm Res 2008; 25: $1511-1520$

[31] Hiremath SP, Soppimath KS, Betageri GV. Proliposomes of exemestane for improved oral delivery: formulation and in vitro evaluation using PAMPA, Caco-2 and rat intestine. Int ] Pharm 2009; 380: 96-104

[32] Balimane PV, Han YH, Chong S. Current industrial practices of assessing permeability and p-glycoprotein interaction. AAPS J 2006; 8: E1-E13

[33] Lin Y, Shen Q, Katsumi H, Okada N, Fujita T, jiang X, Yamamoto A. Effects of labrasol and other pharmaceutical excipients on the intestinal transport and absorption of rhodamine123, a P-glycoprotein substrate, in rats. Biol Pharm Bull 2007; 30: 1301-1307

[34] Seljak KB, Berginc K, Trontelj J, Zvonar A, Kristl A, Gašperlin M. A self-microemulsifying drug delivery system to overcome intestinal resveratrol toxicity and presystemic metabolism. J Pharm Sci 2014; 103: 3491-3500 
[35] Bergamante V, Ceschel GC, Marazzita S, Ronchi C, Fini A. Effect of vehicles on topical application of Aloe vera and Arnica montana components. Drug Deliv 2007; 14: 427-432

[36] Hamid KA, Katsumi H, Sakane T, Yamamoto A. The effects of common solubilizing agents on the intestinal membrane barrier functions and membrane toxicity in rats. Int J Pharm 2009; 379: 100-108

[37] Kommuru TR, Gurley B, Khan MA, Reddy IK. Self-emulsifying drug delivery systems (SEDDS) of coenzyme Q10: formulation development and bioavailability assessment. Int J Pharm 2001; 212: 233-246

[38] Hu ZP, Tawa R, Konishi T, Shibata N, Takada K. A novel emulsifier, labrasol, enhances gastrointestinal absorption of gentamicin. Life Sci 2001; 69: $2899-2910$

[39] Delongeas JL, Vermeil de Conchard G, Beamonte A, Bertheux H, Spire C, Maisonneuve C, Becourt-Lhote N, Goldfain-Blanc F, Claude N. Assessment of labrasol/labrafil/transcutol $(4 / 4 / 2, \mathrm{v} / \mathrm{v} / \mathrm{v})$ as a non-clinical vehicle for poorly water-soluble compounds after 4-week oral toxicity study in Wistar rats. Regul Toxicol Pharm 2010; 57: 284-290
[40] Makhey VD, Guo A, Norris DA, Hu P, Yan J, Sinko PJ. Characterization of the regional intestinal kinetics of drug efflux in rat and human intestine and in Caco-2 cells. Pharm Res 1998; 15: 1160-1167

[41] Hubatsch I, Ragnarsson EGE, Artursson P. Determination of drug permeability and prediction of drug absorption in Caco-2 monolayers. Nat Protoc 2007; 2: 2111-2119

[42] Aditya NP, Shim M, Lee I, Lee Y, Im MH, Ko S. Curcumin and genistein coloaded nanostructured lipid carriers: in vitro digestion and antiprostate cancer activity. J Agric Food Chem 2013; 61: 1878-1883

[43] Xiaoxi C, Murawski A, Patel K, Crespi CL, Balimane PV. A novel design of artificial membrane for improving the PAMPA model. Pharm Res 2008; 25: $1511-1520$

[44] lacomino G, Fierro O, D’Auria S, Picariello G, Ferranti P, Liguori C, Addeo F, Mamone G. Structural analysis and Caco-2 cell permeability of the celiac-toxic A-gliadin peptide 31-55. J Agric Food Chem 2013; 61: 1088-1096 